This PDF is a selection from an out-of-print volume from the National Bureau of Economic Research

Volume Title: Human Capital: A Theoretical and Empirical Analysis with Special Reference to Education (3rd Edition)

Volume Author/Editor: Gary S. Becker

Volume Publisher: The University of Chicago Press

Volume ISBN: 0-226-04119-0

Volume URL: http://www.nber.org/books/beck94-1

Conference Date: $\mathrm{n} / \mathrm{a}$

Publication Date: January 1994

Chapter Title: Human Capital, Fertility, and Economic Growth

Chapter Author: Gary S. Becker, Kevin M. Murphy, Robert Tamura

Chapter URL: http://www.nber.org/chapters/c11239

Chapter pages in book: (p. 323 - 350) 


\title{
Human Capital, Fertility, and Economic Growth'
}

\author{
Gary S. Becker, Kevin M. Murphy, and Robert Tamura
}

\section{Introduction}

Economic growth has posed an intellectual challenge ever since the beginning of systematic economic analysis. Adam Smith claimed that growth was related to the division of labor, but he did not link them in a clear way. Thomas Malthus developed a formal model of a dynamic growth process in which each country converged toward a stationary per capita income. According to his model, death rates fall and fertility rises when incomes exceed the equilibrium level, and the opposite occurs when incomes are less than that level. Despite the influence of the Malthusian model on nineteenth-century economists, fertility fell rather than rose as incomes grew during the past 150 years in the West and other parts of the world.

The neoclassical model of growth responded to the failure of the Malthusian model by essentially ignoring any link between population and the economy. Adjustments in this model take place not in the popula-

' Our research was supported by National Science Fotundation grant SES-8520258 and by National Institute of Child Health and Human Development grant SSP 1 R37 HD22054. We had helpful comments from Edward Prescott, Sherwin Rosen, and Henry Wan and useful assistance from David Meltzer. 
tion growth rate, but in the rate of investment in physical capital. The physical capital stock grows more slowly when per capita income exceeds its equilibrium level, and it grows more rapidly when per capita income is below equilibrium. ${ }^{2}$

Neither Malthus's nor the neoclassicists' approach to growth pays much attention to human capital. Yet the evidence is now quite strong of a close link between investments in human capital and growth. Since human capital is embodied knowledge and skills, and economic development depends on advances in technological and scientific knowledge, development presumably depends on the accumulation of human capital.

Evidence for the twentieth-century United States supports this reasoning. Gross investment in schooling grew much more rapidly in the United States between 1910 and 1950 than gross investment in physical capital (Schultz 1960). Denison (1985) found that the growth in years of schooling between 1929 and 1982 "explained" about 25 percent of the growth in U.S. per capita income during the period. The experiences of nearly one hundred countries since 1960 suggest that education investments in 1960 are an important variable explaining subsequent growth in per capita incomes (see Barro 1989). Considerable circumstantial evidence also indicates that countries grow more rapidly when education and other skills are more abundant.

Our model of growth takes this evidence seriously and departs from both the Malthusian and neoclassical approaches by placing investments in human capital at the center. Crucial to our analysis is the assumption that rates of return on investments in human capital rise rather than decline as the stock of human capital increases, at least until the stock becomes large. The reason is that education and other sectors that produce human capital use educated and other skilled inputs more intensively than sectors that produce consumption goods and physical capital. This leads to multiple steady states: an undeveloped steady state with little human capital and low rates of return on investments in human capital, and a developed steady state with much higher rates of return and a large and perhaps growing stock of human capital.

Our analysis contains elements of both the Malthusian and neoclassical models since fertility is endogenous and rates of return on investments in physical capital decline as its stock increases. The endogeneity of fertility also leads to multiple steady states: a "Malthusian" undevel-

\footnotetext{
2 The convergence of per capita income in the neoclassical growth model may help explain the experience of the developed countries (see Dowrick and Nguyen 1989). However, for the entire world, it fails badly.
} 
oped steady state with high birth rates and low levels of human capital, and a developed steady state with mich lower fertility and abundant stocks of human and physical capital.

Multiple steady states mean that history and luck are critical determinants of a country's growth experience. In our formulation, initial levels of human capital and technology, and snbsequent productivity and other shocks, determine whether a country grows richer over time or stagnates at low income levels. Many attempts to explain why some countries and continents have had the best economic performance during the past several centuries give too little attention to accidents and good fortune.

Our approach relies on the assumption that higher fertility of the present generation increases the discount on per capita future consumption in the intertemporal ntility functions that guide consumption and other decisions. Therefore, higher fertility discourages investments in both human and physical capital. Conversely, higher stocks of capital reduce the demand for children because that raises the cost of the time spent on child care.

Section 2 sets out the basic assumptions of our analysis and derives its main implications in an informal way. Section 3 provides a more rigorous discussion of a special case withont physical capital, but with endogenous fertility and rates of return on human capital that are independent of its stock. Section 4 formally treats the case with both physical and human capital and the case in which the human capital sector uses educated and other skilled inputs more intensively than other sectors.

Section 5 discisses several broad implications of the analysis. Among other issues, it explains why the brain drain occurs invariably from less developed to developed countries, whereas less developed countries import as well as export financial and other tangible capital. We also discriss the "takeoff" period, in which increases in physical and human capital and decreases in fertility are unusially rapid.

Section 6 summarizes the discussion and offers a few concluding comments.

\section{Basic Properties of the Model}

This section first presents several basic assumptions abolit human capital and fertility and then derives in an informal way the properties of two stable steady-state positions. At one, human capital is negligible and fertility is high, while at the other, human capital is widespread and perhaps growing over time and fertility tends to be low. 
The production and rearing of children are very time intensive. This implies that higher wage rates-dıe perhaps to greater human or physical capital per worker-indıce a substitution effect away from fertility by raising the cost of children.

A second assumption about fertility is more novel and comes from recent work by Becker and Barro (1988) on dynastic families. It states that the discount rate applied by the present generation to the per capita consimption of subsequent generations depends negatively on the fertility of the present generation. Becker and Barro motivate the assumption with a ntility function of parents who are altruistic toward their children. The discount rate between generations is determined by the degree of parental altruism toward each child. Diminishing marginal utility implies that the disconnt rate applied to the utility of each child declines as the number of children increases.

A simple formulation is

$$
V_{t}=u\left(c_{t}\right)+a\left(n_{t}\right) n_{t} V_{t+1}
$$

with $u^{\prime}>0, u^{\prime \prime}<0$, and $a^{\prime}<0 ; V_{t}$ and $V_{t+1}$ are the utilities of parents and each child; $c_{t}$ is parental consumption; and $n_{t}$ is the number of children. The degree of altruism per child, $a(n)$, is negatively related to the number of children.

We assıme that the production of human capital is human capital intensive and uses relatively more human capital per unit of ontput than the consilmption, child rearing, and physical capital sectors do. By contrast, the production of physical capital is assumed to nse physical capital as intensively as the consumption sector. The evidence does indicate that the education sector ises much highly educated labor as teachers and researchers, whereas the production of physical capital does not seem to use especially large amounts of physical capital.

In neoclassical models, the rate of return on physical capital investments is assumed to fall as the per capita stock of physical capital increases. A corresponding assumption for human capital is less plansible since human capital is knowledge embodied in people. The benefit from embodying additional knowledge in a person may depend positively rather than negatively on the knowledge he or she already has. There is a similar assumption behind the mastery learning concept in education pedagogy, where learning of complicated mathematics and other materials is more efficient when the building blocks of elementary concepts are mastered (see Bloom 1976).

A positive effect of the stock of human capital on investments in hilman capital is also part of the "nentrality" assumption in the literature 
on the life cycle accumulation of human capital (see the pioneering paper by Ben-Porath [1967]; see also Heckman [1976] and Rosen [1976]), the relation between parents' human capital and the learning of children (Becker and Tomes 1986), and the perpetual economic growth analysis in recent growth models (Becker and Murphy 1988, 1989; Lucas 1988; Tamura 1988, 1989).

The main implication of our two assumptions about human capital investments is that rates of return on human capital do not monotonically decline as the stock of human capital increases. Rates of return are low when there is little human capital, and they grow at least for a while as human capital increases. Eventually, they may begin to decline as it becomes increasingly difficult to absorb more knowledge (see the discussion in Becker and Murphy [1989]).

To discuss the implications of these assumptions about human capital and fertility, consider charts 14 and 15 . Human capital per worker at time $t\left(H_{t}\right)$ is plotted along the horizontal axis and human capital at time $t+1\left(H_{t+1}\right)$ is plotted along the vertical axis; physical capital is ignored for the present. The rate of return on investments in human capital, $R_{h}(H)$, rises with $H$, and it is relatively low at the origin, where $H=0$. The discount rate on future consumption, $[a(n)]^{-1}$, is high at that point because $a(n)$ depends negatively on fertility $(n)$, which tends to be high when $H$ is low because the time spent bearing and rearing children is then cheap. Therefore, the discount rate on the future would exceed the rate of return on investment when $H=0$ :

$$
\left[a\left(n_{u}\right)\right]^{-1}>R_{h} \text { when } H=0 .
$$

This inequality is a necessary and sufficient condition for a steady state when $H=0$ (at $U$ ), for it guarantees that the economy does not want to invest when there is no human capital. Moreover, the steady state is locally stable, for the inequality must continue to hold for small positive values of $H$. Hence, the economy returns over time to $H=0$ for some values of $H>0$. As $H$ increases, $R_{h}$ also increases and $a(\cdot)$ falls as $n$ falls, so that eventually they become equal. Then investment in $H$ becomes positive, but the economy continues to return over time to the steady state with $H=0$, as long as the amount invested is less than the capital that wears out.

However, the amount invested in human capital continues to rise as the stock of human capital increases because the rate of return continues to rise, and the demand for children falls as they become more expensive. Therefore, a steady state emerges when $H$ is sufficiently large that it satisfies the condition 
328

FERTILITY AND ECONOMIC GROWTH

$$
\left[a\left(n^{*}\right)\right]^{-1}=R_{h}\left(H^{*}\right),
$$

where $n^{*}$ is the steady-state fertility rate. If rates of return eventually fall as $H$ gets large, $H^{*}$ refers to a constant level of $H$, as at $L$ in chart 14 . However, if $R_{h}$ asymptotes to a constant level, then $H^{*}$ refers to a constan rate of growth in $H$, shown by the curve $h^{\prime} h^{\prime}$ in chart 15 .

The policy functions $h h$ and $h^{\prime} h^{\prime}$ in charts 14 and 15 give human caial in period $t+1$ as a function of the amount in $t$. The steady states at $H=0$ and $H=H^{*}$ are stable locally since $h h$ and $h^{\prime} h^{\prime}$ are below the steady-state line $H_{t+1}=H_{t}$ for all $H<\hat{H}$ and are above the steady-state

Chart 14.

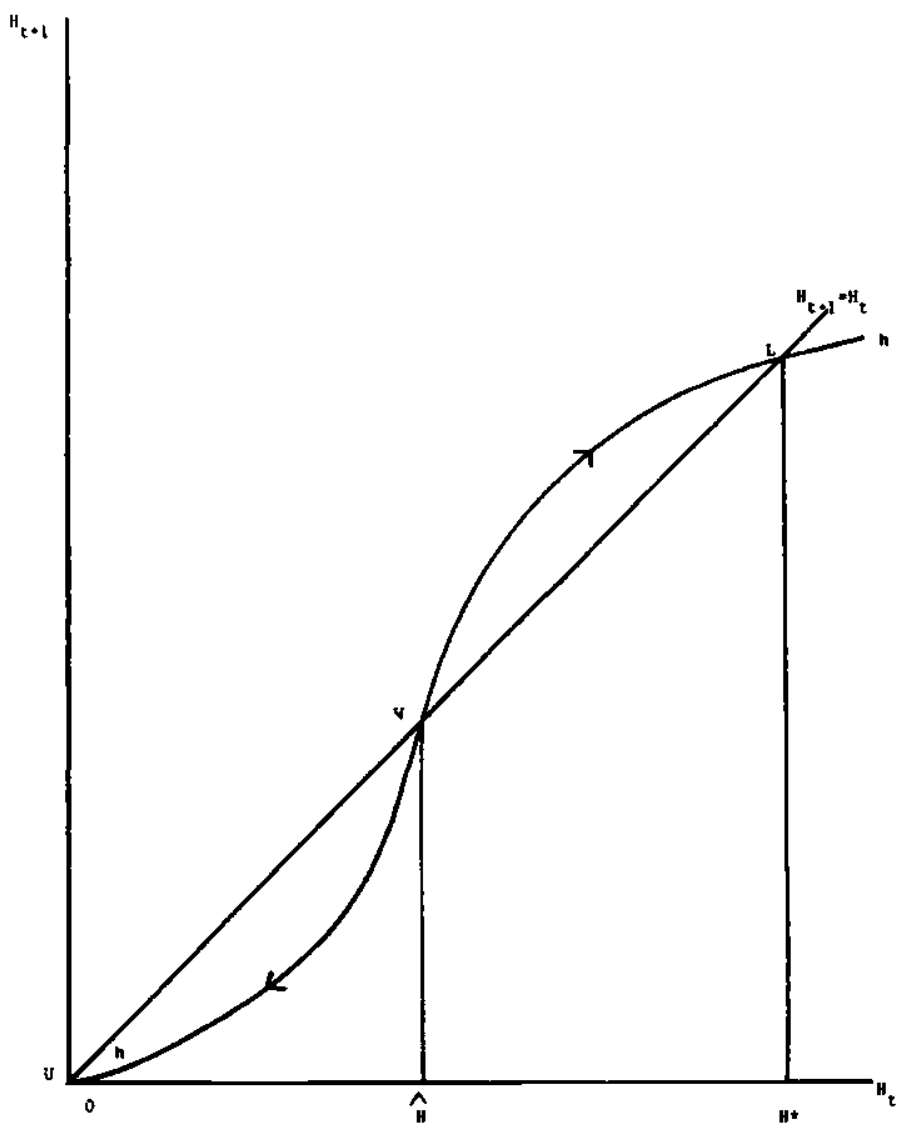




\section{Chart 15.}

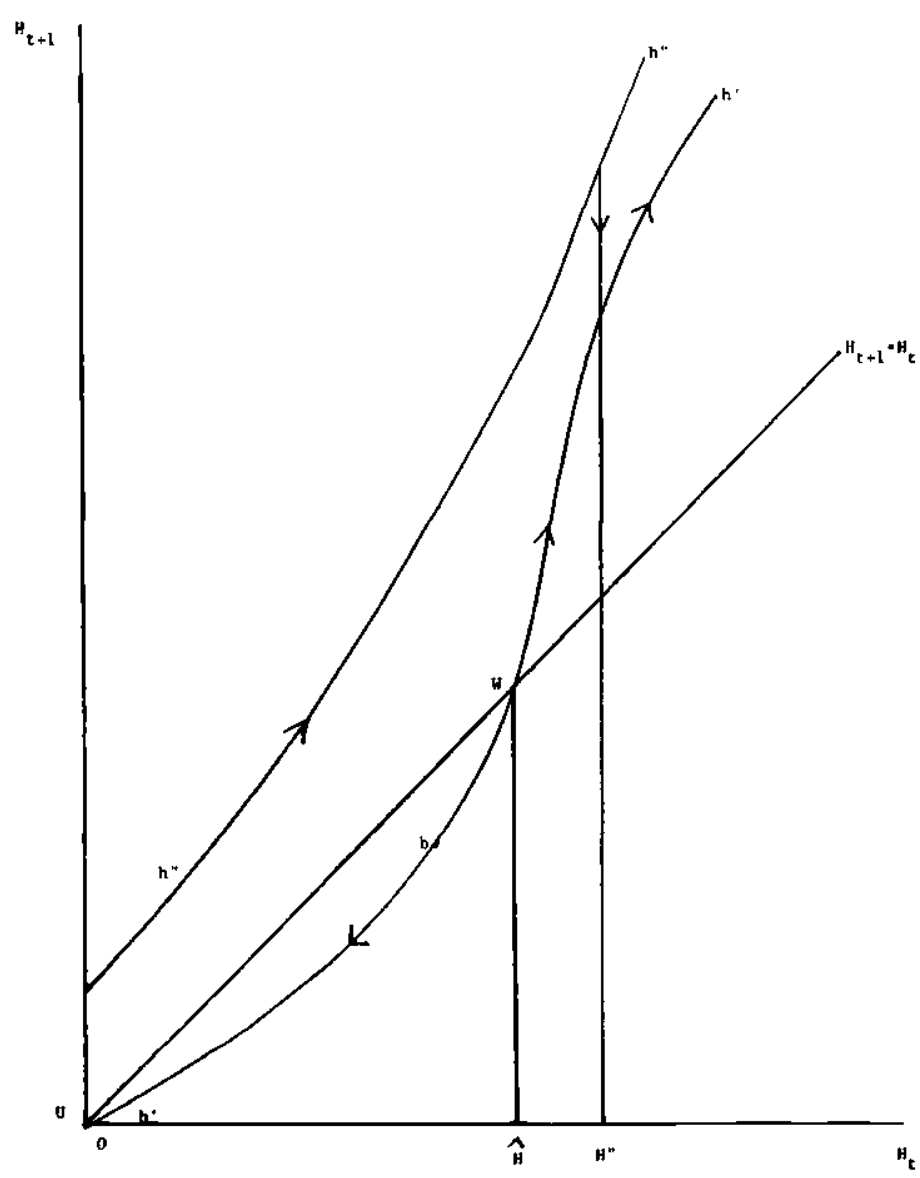

line for all $H>\hat{H}$. The point $W$ at which $H=\hat{H}$ is a third steady state, but it is unstable; negative deviations $(H<\hat{H})$ lead over time toward $H=0$, and positive deviations $(H>\hat{H})$ lead toward $H^{*}$.

The steady-state level $\hat{H}$ is nonoptimal when the program is not globally concave. The unstable steady state $\hat{H}$ is then replaced by a threshold human capital stock $\tilde{H} \neq \hat{H}$. At $\tilde{H}$, a parent is indifferent between reducing and raising the human capital of her children.

It is easy to incorporate physical capital into the story. With the usual assumption that the rate of return on physical capital is very high when there is little physical capital, the equilibrium stock of physical capital is 
positive at the steady state with $H=0$. The equilibrium rate of return on investments in physical capital equals the endogenous discount rate

$$
\left[a\left(n_{u}\right)\right]^{-1}=R_{k} \text { when } H=0, K=K_{u},
$$

where $R_{k}$ is the rate of return on investments in $K$.

The per capita amount of physical capital at the steady state with $H=$ $H^{*}$ is likely to be larger than at the steady state with $H=0$ because the discount rate is lower, although the equilibrium per capita stock of physical capital depends also on the degree of complementarity or substitution in production between $K$ and $H$. However, if $H$ grows at a constant rate in this steady state, so too would the equilibrium stock of physical capital.

The lower and upper stable steady states correspond to undeveloped and developed economies, respectively, where the lower one has smaller per capita incomes, lesser amounts of both human and physical capital per capita, and higher birth rates. Our analysis implies that rates of return on human capital $\left(R_{h}\right)$ tend to be higher in developed economies, whereas rates of return on physical capital $\left(R_{k}\right)$ may be greater or smaller in developed economies depending on birth rates in both steady states and the rate of growth of consumption in the developed steady states.

An undeveloped economy is stuck there unless sufficiently big favorable technology or other shocks raise the policy function above the steady-state line at $H=0$ or increase the stock of human capital above $\hat{H}$. Similarly, an economy would remain developed unless war or other disasters destroy enough human capital to lower it sufficiently below $\hat{H}$ or reduce the policy function below the stead-state line. Even temporary shocks can permanently jar an economy into development if it accumulates enough human capital $(>\hat{H})$ before the shocks are over. By the same token, however, temporary shocks could push an economy toward permanently low incomes if it disinvests enough human capital $(H<\hat{H})$ before the shocks cease.

Human capital has a more fundamental role than physical capital in determining these steady-state equilibria because $R_{h}$ rises, at least for a while, as $H$ increases, while $R_{k}$ falls with $K$. Given the human capital investment function, the initial level of per capita human capital determines where the economy ends up, regardless of the initial stock of physical capital. Although the stock of physical capital may affect the rate of return on investments in human capital, we show in Section 4 that an increase in physical capital could either raise or lower the return on human capital, depending on the degree of substitution between $H$ and $K$ in both production and consumption. 


\section{Fertility and Growth}

The next two sections use specific models to illustrate the type of steadystate equilibrium and dynamics discussed in Section 2. This section highlights fertility, especially the time intensity of rearing children and the effect of the number of children on the rate of discount of future consumption. To concentrate on these properties, we ignore physical capital and assume simple production functions in the consumption, human capital, and fertility sectors.

We also assume that everyone is identical and lives for two periods, childhood and adulthood, works $T$ hours as an adult, and spends all his or her childhood time investing in human capital. A person chooses to have $n$ children at the beginning of the adult period, where $v$ hours and $f$ units of goods are spent rearing each child ( $v$ and $f$ are constants) and each child is endowed with $H^{0}$ units of productive skills. The human capital of children depends on the endowments and human capital $(H)$ of their teachers-parents and the time $(h)$ spent on teaching. Assuming a Cobb-Douglas production function and $H^{0}$ and $H$ as perfect substitutes, we have

$$
H_{t+1}=A h_{t}\left(b H^{0}+H_{t}\right)^{\beta} .
$$

The coefficient $A$ measures the productivity of investments, $b$ gives the number of $H^{0}$ units that are equivalent to one unit of $H$, and $\beta \leq 1$ measures the effect of scale on the production of human capital.

The consumption sector also has a Cobb-Douglas production function:

$$
c_{t}+f n_{t}=D l_{t}\left(d H^{0}+H_{t}\right)
$$

where $c$ is per capita adult consumption, $D$ measures the productivity of this sector, $l$ is the time spent by each adult producing consumer goods, and $d$ is the rate of exchange between $H^{0}$ and $H$. We assume that the consumption sector has constant returns to scale in the effective amount of time, $l\left(d H^{0}+H\right)$. By summing over the time allocated to fertility, consumption, and investment, we get the time budget equation

$$
T=l_{t}+n_{t}\left(v+h_{t}\right)
$$

This section concentrates on the effects of fertility by assuming that $b=d=1$ to eliminate any comparative advantage from using human 
capital in the human capital sector instead of in the consumption sector. Both sectors have a comparative advantage relative to the production of children. lt is also assımed that $\beta=1$ : the economy accumılates human capital without running into diminishing returns.

Parents maximize the dynastic utility function in equation (1) (or state planners maximize the intergeneration utility function in [1]) with respect to fertility and the time spent investing in human capital. We simplify the utility function with

$$
a(n)=\alpha n^{-\varepsilon}, u(c)=\frac{c^{\boldsymbol{\sigma}}}{\boldsymbol{\sigma}},
$$

where $0 \leq \varepsilon<1$ and $0<\sigma<1, \alpha$ is the degree of pure altruism (when $n=1$ ), and $\varepsilon$ is the constant elasticity of altruism per child as their number increases.

The arbitrage condition between per capita consumption in periods $t$ and $t+1$ is

$$
\frac{u^{\prime}\left(c_{t}\right)}{a u^{\prime}\left(c_{t+1}\right)}=\alpha^{-1} n_{t}^{e}\left(\frac{c_{t+1}}{c_{t}}\right)^{1-\sigma} \geq R_{h t}=1+r_{h t}
$$

where $r_{h}$ is the rate of return on investments in human capital, and equality holds when investments are positive. The rate of return is determined from

$$
\begin{aligned}
R_{h t} & =A\left(T-v n_{t+1}\right) \\
& =A\left(l_{t+1}+h_{t+1} n_{t+1}\right) \cdot{ }^{3}
\end{aligned}
$$

It is not surprising that the rate of return depends positively on the productivity of investments $(A)$. Since the rate of return measures the effect

\footnotetext{
${ }^{3}$ To calculate the Euler equation for human capital investment, rewrite the Bellman equation using the learning technology (eq. [5]), the budget constraint (eq. [6]), and the time constraint (eq. [7]) to yield
}

$$
\begin{aligned}
V_{t}\left(H_{t}\right)= & \max \left[\frac{\left(D\left(d H^{\mathrm{o}}+H_{t}\right)\left\{T-n_{t}\left[v+H_{t+1} A^{-1}\left(b H^{D}+H_{t}\right)^{-\beta}\right]\right\}-f n_{t}\right)^{\sigma}}{\sigma}\right. \\
& \left.+\alpha n_{t}^{1-\varepsilon} V_{t+1}\left(H_{t+1}\right)\right] .
\end{aligned}
$$

Differentiating with respect to $H_{t+1}$ produces

$$
-c_{t}^{\sigma-1} D\left(d H^{0}+H_{t}\right) n_{t} A^{-1}\left(b H^{n}+H_{t}\right)^{-\beta}+\alpha n_{t}^{1-\varepsilon} V_{t+1}^{\prime} \leq 0 .
$$

Using the envelope theorem provides

$$
V_{t+1}^{\prime}=c_{t+1}^{\sigma-1} D\left\{T-n_{t+1}\left[v+H_{t+2} A^{-1}\left(b H^{N}+H_{t}\right)^{-\beta}\right.\right.
$$


on $c_{\mathrm{t}+1}$ of increasing $H_{\mathrm{t}+1}$, it also depends on the productivity of greater $H_{t+1}$, which depends on $l_{t+1}, n_{t 1}^{+}$, and $h_{t+1}$.

The first-order condition for maximizing ntility with respect to fertility comes from differentiating $V_{t}$ in equation (1) with respect to $n_{r}$ :

$$
(1-\varepsilon) \alpha n_{\imath}^{-\varepsilon} V_{t+1}=u^{\prime}\left(c_{t}\right)\left[\left(v+h_{t}\right)\left(H^{0}+H_{t}\right)+f\right] \text {. }
$$

The second-order condition requires that $\varepsilon+\sigma<1$ and $u^{\prime \prime}<0$ (see Becker and Barro 1988). The left-hand side of equation (11) gives the marginal utility from an additional child, and the right-hand side gives the sum of time and goods costs of producing and rearing a child. Costs depend on the endogenous time spent investing in children as well as the fixed time $(v)$ and goods $(f)$ inputs.

At the steady state with $H=0$, equation (9) becomes the strict inequality

$$
n_{u}^{e}>\alpha A\left(T-v n_{u}\right),
$$

with $n_{u}$ being the steady-state fertility rate. This inequality will hold when parents have a sufficiently large family. The first-order condition for fertility in equation (11) simplifies in the steady state with $H=h=0$ to

$$
\frac{\left(T-v n_{u}\right) H^{0}-f n_{u}}{v H^{0}+f}=\frac{\sigma\left(1-\alpha n_{u}^{1-\varepsilon}\right)}{(1-\varepsilon) \alpha n_{u}^{-\varepsilon}} .
$$

The left-hand side gives the financial rate of return from children in the steady state: the ratio of adult consumption to the consumption forgone to produce a child. The rate of return from children is greater when endowments are larger and the time $(v)$ and goods $(f)$ spent to produce children are smaller. Therefore, parents have many children when they are cheap to produce and yet are reasonably well endowed with earning power. A sufficiently high rate of return from having children would induce parents to have enough children to discourage any investments

$$
\text { - } \left.\left.\left.\beta H_{t+2} A^{-1}\left(d H^{0}+H_{t+1}\right) b H^{0}+H_{t+1}\right)^{-(1+\beta)}\right]\right\} .
$$

When $\beta=1$ and $b=d$, the last two terms in square brackets drop ott, leaving

$$
V_{t+1}^{\prime}=c_{t+1}^{\sigma-1} D\left(T-n_{t+1} v\right) \text {. }
$$

Substituting this into the Euler equation yields

$$
-c_{t}^{\sigma-1}+\alpha n_{t}^{\varepsilon} c_{t+1}^{\sigma-1} A\left(T-\tau m_{t+1}\right) \leq 0 .
$$


in the children's human capital. Then $H=0$ would be a steady-state equilibrium.

This steady state must be stable for some positive values of $H$. Since the rate of return on investments is strictly less than the discount rate when $H=0$, it must also be less for some $H_{t}>0$. Then $H_{t+1}=0$, and the economy returns to the steady state in one generation. Clearly, the steady state is also stable for some $H_{t}$ with positive investment when $H_{t+1}$ $<H_{i}$.

An increase in the stock of human capital raises per capita income and hence has a positive income effect as well as a negative substitution effect on the demand for children. The income effect dominates in economies with little human capital if components of $f$-necessities such as food, housing, and clothing-are the main cost of rearing children, as determined from

$$
\frac{f}{v\left(H^{0}+H\right)+f}>1-\sigma .
$$

A positive relation between fertility and per capita income is a Malthusian property that helps stabilize the steady state with $H=0$. Higher fertility when $H>0$ raises the discount on future consumption and lowers the rate of return on investments. Both effects reduce the incentive to invest and help return the economy to the steady state.

However, our analysis implies that the Malthusian assumption of a positive relation between fertility and income is a myopic view of the effects of development on fertility that may hold when countries have only a little human capital, but does not hold when they manage to reach a moderate stage of development. Even if parents do not invest in children, the cost of the time input must rise as $H$ increases, which reverses the inequality in (14) when $H$ is large enough. Then the substitution effect begins to dominate the income effect, and fertility declines with further increases in $H$. Eventually, the rate of return on investment in children becomes as large as the discount rate, and parents start investing in children $(h>0)$. The amount invested at first is insufficient to maintain the stock of human capital, and the economy returns over time to the steady state (see point $b$ in chart 15 ).

Investments rise further as the stock of human capital increases further. If investments are sufficiently productive $(A)$ and there are appropriate values of $v, \varepsilon$, and $\sigma$ (see eq. [18] below), the amount invested would exceed the initial stock for sufficiently high initial stocks of $H$. Then $H_{t}$ does not decline over time toward $H=0$, but instead continues to grow over time. As $H$ grows, the endowment $H^{0}$ becomes negligible 
relative to time costs, $(v+h) H$. The economy converges to a steady-state growth path (see Tamura [1989] for a discussion of the stability of this path), with a constant fertility rate $\left(n^{*}\right)$, a constant time $\left(h^{*}\right)$ spent investing in $H$, and a constant rate of growth over time in both $H$ and $c\left(g^{*}\right)$.

The steady-state values $n^{*}$ and $h^{*}$ are determined from the first-order conditions for $n$ and $h$ when $f$ and $H^{0}$ are negligible:

$$
\begin{gathered}
(1-\varepsilon) \alpha n^{*-\varepsilon} V_{t+1}=u^{\prime}\left(c_{t}\right)\left(v+h^{*}\right) H_{i}, \\
A \alpha n_{*}{ }^{-\varepsilon} \frac{d V_{t+1}}{d H_{t+1}}=u^{\prime}\left(c_{t}\right),
\end{gathered}
$$

where $d V_{t+1} / d H_{t+1}^{*}$ is evaluated along the steady-state path with

$$
1+g^{*}=\frac{c_{t+1}}{c_{t}}=\frac{H_{t+1}}{H,}=A h^{*}
$$

Dividing equation (16) by (15) and substituting $\sigma=d \log V_{i+1} / d H_{t+1}$ and $h^{*}=\left(1+g^{*}\right) / A$, we get

$$
1+g^{*}=\frac{\sigma v A}{1-\sigma-\varepsilon}
$$

and

$$
h^{*}=\frac{\sigma v}{1-\sigma-\varepsilon} .
$$

The steady-state fertility rate is found by substituting into equations (9) and (10):

$$
\alpha n^{*-\varepsilon}\left(T-v n^{*}\right)=A^{-1}\left(1+g^{*}\right)^{1-\sigma} .
$$

Steady-state growth exists if the combination of $A, v, \sigma$, and $\varepsilon$ on the right-hand side of equation (18) exceeds one. Equations (18) and (20) show that an increase in the productivity of investments $(A)$ raises both steady-state growth and fertility. Higher fixed-time costs of children (v) or a more elastic altruism function $(\varepsilon)$ reduces $n^{*}$ and raises $g^{*}$ as families substitute away from children when they become more expensive and toward greater investment in each child.

Greater altruism $(\alpha)$, and lower adult mortality that expands adult 
time (T), both raise $n^{*}$ but do not affect $g^{*}$ (see Meltzer [1989] for a general discussion of the effects of mortality within this model). Note, however, that the absence of any effect of $\alpha$ and $T$ on $g^{*}$ results from the constant elasticity form assumed for $u(c)$ and $a(n)$. With other functional forms, increases in $\alpha$ or $T$ could either raise or lower the steadystate growth rate.

The analysis implies that fertility and the steady-state rate of growth in per capita incomes could be either negatively or positively related among countries, or over time in a given country, depending on why growth rates differed. If $g^{*}$ differed mainly because the productivity of investments differed, $n^{*}$ and $g^{*}$ would be positively related; if $g^{*}$ differed mainly because the cost of children differed, $g^{*}$ and $n^{*}$ would be negatively related; and if $g^{*}$ differed mainly because adult mortality or the degree of altruism toward children differed, $g^{*}$ and $n^{*}$ might well be unrelated. Studies of growth rates among countries since 1950 find that they are very weakly negatively related to fertility rates (see Barro 1989). This suggests that growth rates do not differ mainly because of differences in the productivity of investments in human capital.

Our analysis does imply that the level of per capita income and fertility would be strongly related. This is easily seen by comparing $n_{u}$ in equation (13) with $n^{*}$ in equation (20): $n_{u}>n^{*}$ for all values of $g^{*} \geq 0$. Therefore, countries with low levels of human capital that have not undergone much development would have higher fertility than developed countries with much human capital. It is well known that the negative relation among countries between the fertility rate and the level of per capita real income is very strong (see, e.g., the evidence in Tamura [1988, 1989]).

Since we have been assuming that the value function $V$ is concave, the optimal human capital in period $t+1$ is a continuous function of the human capital in $t$. With the steady state at $H=0$ stable for some $H>$ 0 and the steady-state growth path stable for some $H$, there must also be a steady state with a constant positive level of $H$ and a constant $n$; in chart 15 , this steady state is at $W$ where $H=\hat{H}$, and the policy function intersects the line $H_{t+1}=H_{t}$. These steady-state values of $H$ and $n$ are determined from the first-order conditions in equation (19) with $g=0$ and a first-order condition for $n$.

A comparison of equation (20) when $g=0$ with equation (12) shows that $n_{d}<n_{u^{\prime}}$. Even if $n$ and $H$ are positively related for $H$ near $H=0, n$ must decline below its level at $H=0$ before the steady state at $H=\hat{H}$. Moreover, equation (20) shows that $n^{*}<n_{d^{\prime}}$ fertility is lower when $H$ is growing at a constant rate than when $H$ is constant. The economy substitutes away from children as human capital and the time cost of raising children increase. 
When a steady state with $H=0$ exists, the steady state with positive human capital is locally and globally unstable (see Tamura [1989] for a formal proof). As chart 15 shows, the economy moves over time to $H=$ 0 for all $H<\hat{H}$, and it moves to steady-state growth for all $H>\hat{H}$. The instability of this steady state results from the negative relation between fertility and human capital. The decline in fertility when $H$ increases above $\hat{H}$ lowers the discount rate on future consumption and also raises the rate of return on investments. Both forces raise investments and next period's human capital relative to this period's. With $H_{t+1}>H_{t}$, fertility falls further and the process continues.

Indeed, if this interaction between $n$ and $H$ is strong enough, the value function becomes convex. Then the function that relates $H_{t+1}$ to $H_{t}$ has a jump at some capital stock $\tilde{H}$. The lower leg lies below the steady-state line, with $H_{t+1}<H_{t}$ for all $H_{t}<\tilde{H}$. The upper leg lies above the steadystate line, with $H_{t+1}>H_{t}$ for all $H_{t}>\tilde{H}$. Although $\tilde{H}$ is not a steadystate solution to the first-order conditions because this solution does not maximize utility if $V$ is convex, $\hat{H}$ does have the properties of an unstable steady state.

The policy functions become discontinuous even for "normal" values of the parameters. The discontinuous relation between $H_{t+1}$ and $H_{t}$ at $H=\tilde{H}$ is matched by a discontinuous relation between $n_{t}$ and $H_{t}$ at $H=$ $\tilde{H}$. The jump in investment when $H$ increases slightly beyond $H=\tilde{H}$ goes together with a fall in fertility. Since the interaction between $n$ and $H$ produces the convexity of $V$, it is no surprise that they both are discontinuous functions of the human capital stock. However, all the adjustment from a switch between the decay regime and the growth regime occurs through investments and fertility, leaving consumption unaffected (see Tamura [1989] for a formal proof). These results can be seen in chart 17 below.

\section{Comparative Advantage in the Production of Human Capital}

In modern economies, the human capital sector relies on skilled and trained labor more than the consumption sector does. The teaching sector has highly educated employees, while many services and some goods rely on unskilled labor. Our analysis captures this difference in a simple way if the endowment $\left(H^{0}\right)$ is less important in the production of human capital, that is, if $b<d$ in the production functions for $H$ and $c$ in equations (5) and (6).

If $H$ is small relative to $H^{0}$ and if $\beta$ in equation (5) is close to one, rates of return increase as a person accumulates more human capital. There- 
fore, the economy should be more efficient with specialization in the accumulation of human capital: teachers in the human capital sector should have more human capital than workers in the consumption sector. However, such specialization may not be feasible if the capital market, especially the market between generations, is undeveloped. Teachers may be unable to borrow the resources to finance very great investments in human capital. This paper makes the strong assumption that because of such capital market difficulties, specialization is not feasible and everyone has the same human capital, even when returns increase as a person accumulates more human capital (Becker and Murphy [1989] analyze efficient specialization between teachers and workers).

We introduce physical capital into the analysis by assuming that physical capital is accumulated consumer goods that do not wear out. The consumption sector is assumed to use physical capital more intensively than the human capital sector, and we treat the simple case in which human capital does not use any physical capital at all. The Cobb-Douglas function in equation (6) is extended to include physical capital:

$$
c+f n+\Delta K=D\left[l\left(d H^{0}+H\right)\right]^{\gamma} K^{1-\gamma},
$$

where $\Delta K$ is the net (and gross) investment in physical capital. The human capital production function is still given by equation (5), with $\beta$ $\leq 1$.

If the human capital sector uses human capital much more intensively than the consumption sector-if $b$ is much less than $d$-the rate of return on investments in human capital would be low when $H=0$ and would rise for a while as $H$ increases, even if $\beta<1$. The rate of return on $H$ when $H=0$ would be below the discount rate on future consumption even with moderate levels of fertility, and hence of the discount rate. Therefore, the comparative advantage of the human capital sector in using human capital raises the likelihood of a stable steady state at $H=0$.

The equilibrium conditions for the steady state are

$$
R_{k}=\alpha^{-1} n_{u}^{\varepsilon}>R_{h}
$$

with

$$
R_{k}=1+(1-\gamma)\left(c_{u}+f n_{u}\right) K_{u}^{-1}
$$

and 


$$
R_{h}=A\left(T-v n_{u}\right) \frac{\left(b H^{0}\right)^{\beta}}{d H^{0}}
$$

Clearly, for a sufficiently small $b, R_{h}<\alpha^{-1} n_{u}^{\varepsilon}$ for any positive valıe of $n_{u}$. Since the rate of return on $K$ goes to infinity as $K \rightarrow 0, K_{u}$ must be positive. Therefore, the rate of return on physical capital must exceed that on human capital at this steady state.

When $H$ is larger relative to $H^{\circ}, b$, and $d$, the comparative advantage of the human capital sector in the use of $H$ becomes unimportant. With $\boldsymbol{\beta}=1$, the economy approaches a steady-state growth path as $H$ increases, where fertility is constant and human capital, physical capital, and per capita consilmption all grow at the rate $g^{*}$, given by

$$
1+g^{*}=\frac{H_{t+1}}{H_{t}}=\frac{K_{t+1}}{K_{t}}=\frac{c_{t+1}}{c_{t}}=\frac{\tilde{\sigma} v A}{1-\sigma-\varepsilon},
$$

with $\tilde{\sigma}=\gamma \sigma$.

The slight difference between the right-hand side of this equation and the right-hand side of equation (18) is that $\partial \log V / \partial \log H=\gamma \sigma<\sigma$ along the steady-state growth path when consumption depends also on physical capital. The ratio of $K$ to $H$, constant along the steady-state path, is determined by the condition

$$
A\left(T-v n^{*}\right)=R_{h}=R_{k}=\alpha^{-1} n^{*} \varepsilon\left(1+g^{*}\right)^{1-\alpha} .
$$

Since the discount rate on future consumption $[a(n)]^{-1}$ depends negatively on fertility, the interest rate with steady-state growth would be less than in the undeveloped steady state if fertility were sufficiently lower in the growth equilibrium to make the right-hand side of equation (26) less than the middle term of equation (22). This implies that the rate of return on $K\left(R_{k}\right)$, which equals the interest rate, could be larger or smaller in steady-state growth compared with the undeveloped equilibrium. An increase in the steady-state growth rate due to a change in $A$ or another parameter could mean a lower interest rate and rate of return on physical capital if fertility fell enough. These resılts are quite different from those in the neoclassical model, where interest rates and rates of return on physical capital are positively related to the growth rate because the discount rate is assumed to be constant.

Since $R_{h}$, the rate of return on human capital, equals $R_{k}$ in the growth equilibrium but is less than $R_{k}$ in the undeveloped equilibriım, $R_{h}$ must increase relative to $R_{k}$ as an economy moves between these equilibria. lndeed, $R_{h}$ must be higher in the steady-state growth equilibrium than 
in the undeveloped equilibrium even if $R_{k}$ and the interest rate are lower. The reason is that $R_{k}$ can be lower only if fertility is lower, but lower fertility implies that $R_{h}$ is higher; compare the left-hand side of equation (26) with the right-hand side of equation (24) when $\beta=1$ and $b<d$.

As $H$ and $K$ get larger, fertility is encouraged by an income effect, but it is discouraged by a substitution effect from the higher cost of time. Fertility would be lower in the growth equilibrium than in the undeveloped equilibrium if the substitution effect dominates: if parents want few children when they are expensive. Empirically, fertility is much lower in richer than in poorer countries, which suggests that the substitution effect does dominate. The lower fertility in richer countries implies that interest rates and rates of return on physical capital might also be lower in richer countries.

The phase diagram in chart 16 helps analyze the stability of the steadystate growth equilibrium and the dynamic paths of human capital and physical capital. The point $U$ is the steady state with $H=0$ and $K>0$, and the slope of the ray $O p$ gives the ratio of $K$ to $H$ along the steadystate growth path. The isocline $\dot{K}=0$ is the locus of all combinations of $K$ and $H$ that lead to zero investment in $K$; similarly, for the isocline $\dot{H}=$ 0 . Since $U$ is a steady-state equilibrium, both isoclines go through $U$.

An increase in $K$ discourages investment in $K$ because $R_{k}$ declines as $K$ increases. An increase in $H$ has conflicting effects on the incentive to invest in $K$. It encourages investment because $K$ and $H$ are complements in production (see eq. [21]) and if an increase in $H$ reduces fertility. However, an increase in $H$ would discourage investment in $K$ if it lowers the marginal utility of future consumption by raising investment in $H$. We assume that, on balance, an increase in $H$ encourages investment in $K$, so that the isocline $\dot{K}=0$ is positively sloped, as in chart 16 .

An increase in $K$ has conflicting effects on investments in $H$ since it raises the cost of the time spent investing in $H$, but it also raises the marginal utility of future consumption by reducing investment in $K$ and perhaps by reducing fertility. For given fertility, the net effect of an increase in $K$ on investment in $H$ depends on the elasticity of substitution in production compared to that in consumption. ${ }^{4}$ Chart 16 assumes that,

${ }^{4}$ Let $\alpha$ be the discount factor (we assume fertility is fixed), $w_{t}$ the wage in pertod $t$, and $c_{t}$ the corresponding level of consumption. The first-order condition for human capital with $\log$ utility is simply

$$
\frac{w_{t}}{c_{t}}=A \alpha \frac{w_{t+1}}{c_{t+1}},
$$


on balance, an increase in $K$ discourages investment in $H$. So $\dot{H}=0$ is positively sloped since an increase in $H$ raises $R_{h}$ and hence investment in $H$.

The isoclines $\dot{H}=0$ and $\dot{K}=0$ intersect not only at $U$ but also at an unstable steady state at $W$. An economy that begins to the right of the stable manifold $M$ through $W$ grows over time toward the path given by $O p$ (see curve $b$ in chart 16), whereas an economy that begins to the left of $M$ declines over time toward point $U$ with $H=0$ (see curve $a$ ). Only economies that begin along $M$ end up at $W$. The increasing returns to $H$ and the likely decline in $n$ as $H$ increases are what destabilize the steady state at $W$. These effects could be strong enough to make the value function $V$ convex, and hence the relation between $n_{t}, H_{t+1}$, and $H_{t}$ discontinuous, although the relation between $c_{t+1}$ and $H_{t}$ is continuous (chart 17 gives an example).

The curve $b$ in chart 16 shows that $H$ grows faster than $K$ when an economy starts off near the steady state at $W$. Then the ratio of $K$ to $H$ falls as the steady-state growth path $O p$ is approached. Human capital in the United States apparently did grow faster than physical capital since the turn of the century (Schultz 1960), and human capital now accounts for a large fraction of all U.S. capital (see the estimates in Jorgenson and Fraumeni [1989]).

If a war or other disaster destroys some physical capital, rates of return on $K$ and investments in $K$ increase. Investments in $H$ also increase if the isoclines for $\dot{H}$ are positively sloped. If the economy had been on the growth path, $H$ and $K$ would grow more rapidly over time after the disas-

and the first-order condition for physical capital is simply

$$
\frac{1}{c_{t}}=\alpha \frac{r_{t+1}^{k}}{c_{t+1}},
$$

where $r_{t+1}^{k}$ is the marginal product of capital in period $t+1$. Rewriting these equations as

$$
\left(\frac{H_{t+1}}{H_{t}}\right)\left(\frac{w_{t} H_{t}}{c_{t}}\right)=A \alpha\left(\frac{w_{t+1} H_{t+1}}{c_{t+1}}\right)
$$

and

$$
\frac{k_{t+1}}{c_{t}}=\alpha \frac{k_{t+1} r_{t-1}^{k}}{c_{t+1}},
$$

we see that if human capital grows at the fixed rate $A \alpha$, the first equation will be satisfied since labor's share is fixed with Cobb-Douglas functions. If the savings rate is constant, then $k_{t+1} / c_{t}$ is constant, and the second equation will be satisfied since capital's share is also fixed. 
Chart 16.

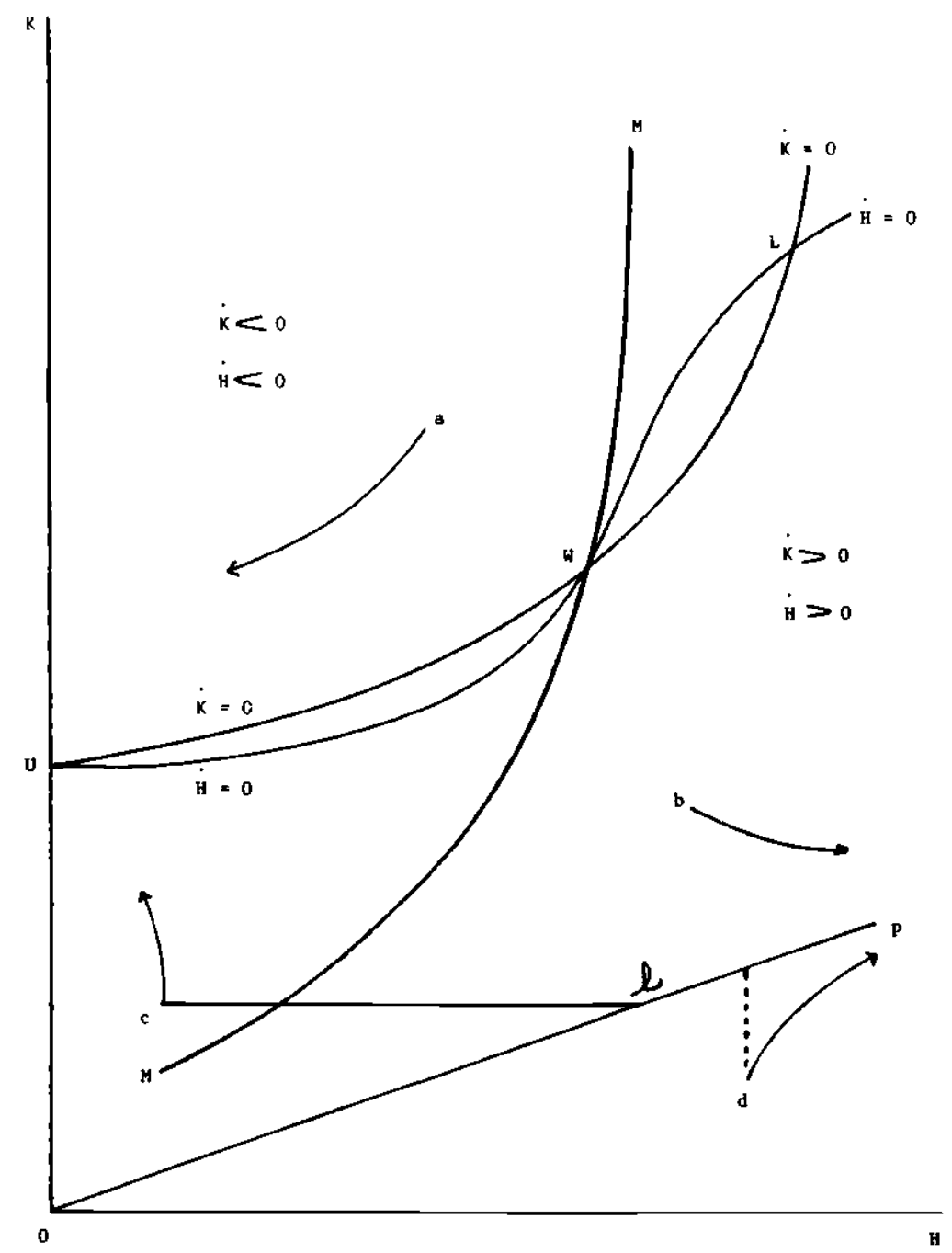

ter than they did before. This implies that the stock of human capital would be greater at any future year than it would have been without the destruction of physical capital. Since the ratio of $K$ to $H$ approaches the same equilibrium ratio that existed before the disaster, $K$ must at some future year also exceed the level it would have reached had the disaster not occurred. Since both $H$ and $K$ exceed the levels they would have 

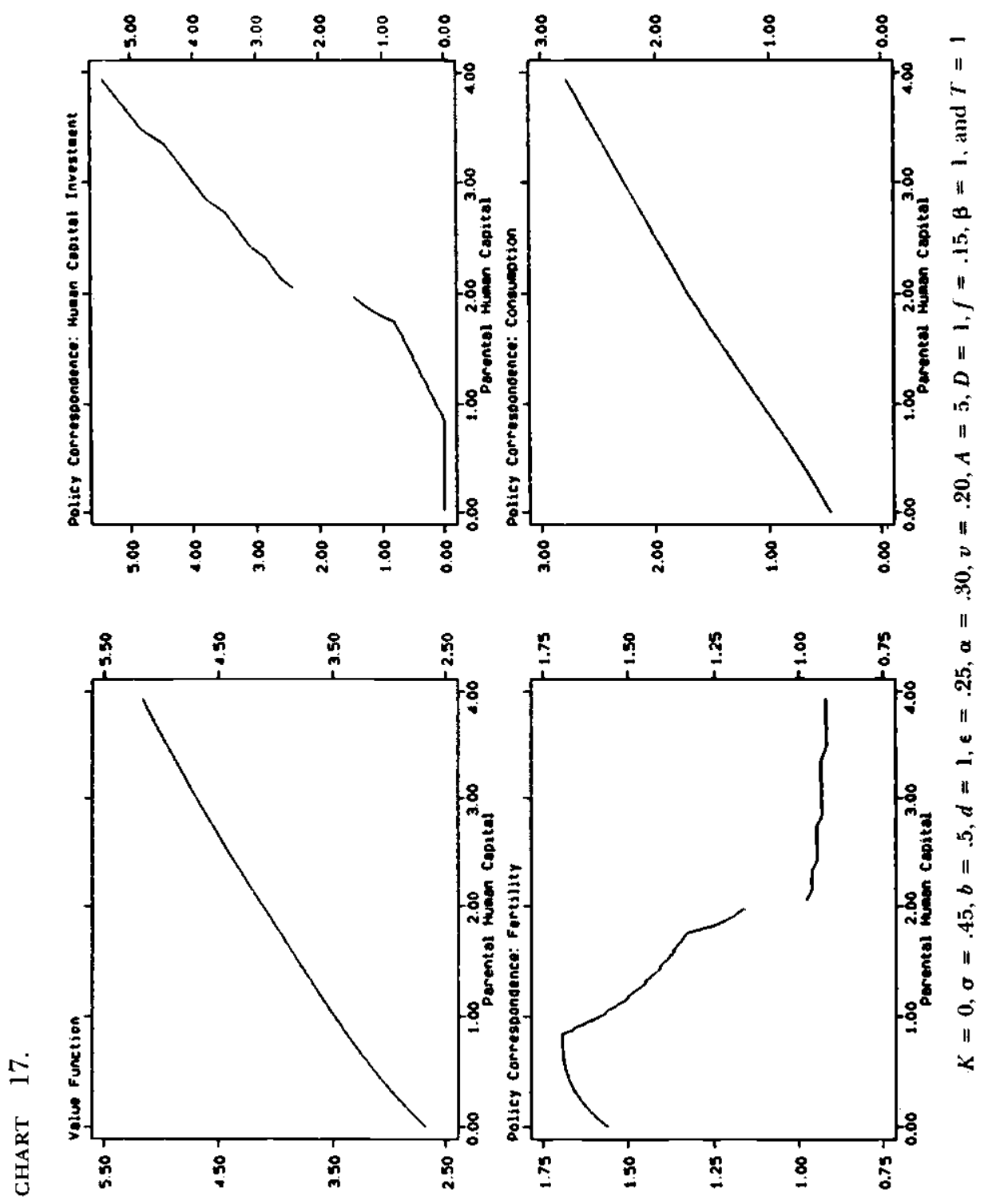
had, per capita income must also eventually surpass the levels it would have reached!

It might appear from this conclusion that destruction of physical capital should be encouraged, for per capita incomes eventually exceed the levels they would have reached. But initial declines in per capita income dominate any eventual increase for the generation that experiences the disaster since its dynastic utility is reduced.

The story is quite different when a disaster destroys human capital, as when a conqueror kills off the educated class. Since investments in both $H$ and $K$ are discouraged, the economy would always have lower per capita incomes than if $H$ had not been destroyed. Indeed, if enough human capital is destroyed-if the economy is moved in chart 16 from point $l$ on the growth path to a point $c$ that is to the left of the manifold $M$-the economy never returns to the growth path. Instead, it sinks toward the undeveloped steady state at $U$.

If the coefficient $\beta$ in equation (5) is less than one, the rate of return on $H$ eventually falls as $H$ increases. Then a steady-state growth equilibrium does not exist, but it is replaced by a stable steady state with constant levels of $H, K$, and $n$ (see point $L$ in charts 14 and 16). With $\beta<1$, the slope of the isocline $\dot{H}=0$ in chart 16 begins to decrease as $H$ gets larger and intersects $\dot{K}=0$ again at point $L$. The ratio of $K$ to $H$ is lower at $L$ than at $W$ but is higher than along the growth path $O p$. The steady state at $L$, like the steady-state growth path, is stable for all initial quantities of $H$ and $K$ that are to the right of the manifold $M$.

\section{Discussion}

Malthus did not pay much attention to human capital, as he assumed that parents were concerned only about the number of children they have. His conclusion that ebbs and flows in birth (and death) rates help maintain wage rates at a constant level is valuable in understanding longrun developments in England and elsewhere prior to his time. But the Malthusian world was shattered forever by the persistent growth in incomes and decline in birth rates that began in the West during the nineteenth century.

The undeveloped steady state in our model has Malthusian properties, for human capital is negligible, fertility is high, and changes in birth rates may help the economy to return to this steady state when it is not too far away. However, our analysis indicates that Malthusians have a myopic view that is inappropriate when economies manage to diverge enough from the undevelopment "trap." Economies would continue to 
develop and diverge from that steady state if technological and other shocks either raise the policy functions above the steady-state line or raise the stocks of human and physical capital sufficiently, for example, if human capital is raised above the unstable steady-state amount $H$ in charts 14 and 15. Improved methods to use coal, better rail and ocean transports, and decreased regulation of prices and foreign trade are some changes that helped trigger the early growth of the West (see the discussion in Rosenberg and Birdzell [1986]).

Considerable luck is needed in the timing and magnitude of shocks to give a sufficiently big push to investments in human and physical capital. But very unlikely configurations of events do occur in the course of thousands of years of history. We believe that the West's primacy, which began in the seventeenth century, was partly due to a "lucky" timing of technological and political changes in the West.

Even temporary events, if they are strong enough, can permanently wrench an economy away from undevelopment. If temporary events lead to favorable initial conditions, the economy continues to grow even without the stimulus of major additional innovations or other events similar to those that got the process started. Suppose that a sequence of events raised the policy function temporarily from $h^{\prime} h^{\prime}$ in figure 2 to $h^{\prime \prime} h^{\prime \prime}$. The economy moves along this function and accumulates $H^{\prime \prime}$ units of human capital by the time these events cease and the policy function returns to $h^{\prime} h^{\prime}$. If new technologies had raised the demand for human capital, the stimulus would cease when these technologies were fully exploited, as long as no further technological advances emerge. Nevertheless, the economy continues to invest in human capital because it had accumulated enough for the process to become self-generating. Analytically, growth displays "state" or "path" dependence, and initial conditions count (see Arthur [1988] for a good discussion of such path dependence in the location of "silicon valleys"; see also David [1985]).

According to our analysis, at some point in the growth process, economies experience periods of particularly rapid accumulation of human and physical capital and declines in birth rates and family size. This happens near the unstable steady states at $W$ in charts 14,15 , and 16 and near the points of discontinuity in chart 17 . These periods of rapid change are reminiscent of the "takeoff" in Rostow's theory of growth (see Rostow [1963] for an empirical evaluation of his analysis). Takeoffs in our approach are driven by increasing returns to investments in human capital and increased costs of children as capital is accumulated. An economy that starts at point $W$ is posed either to take off toward sustained economic growth or to fall back toward stagnation.

Needham (1969) presents a well-known discussion of why the indus- 
trial revolution did not begin in medieval China, even though that country was much more advanced technologically than medieval Europe. He emphasizes the policies of the mandarin bureaucrats (a view criticized by Chao [1986]; see also Jones's [1988] criticisms of Needham), but he also recognizes the delicacy and instability of the prior European equilibriım: "These many diverse discoveries and inventions had earthshaking effects in Europe, but in China the social order of bureaucratic fendalism was little disturbed by them. The built-in instability of European society must therefore be contrasted with a homeostatic equilibrium in China" (p. 214; our italics).

Our analysis implies that rates of return on education and other human capital are higher in developed than in undeveloped countries, both absolutely and relative to rates on physical capital. Rates of return on physical capital may be either higher or lower in developed countries, depending on fertility and rates of growth in consumption. Consequently, we readily explain why the "brain drain" of educated and skilled persons almost invariably occurs from poorer to richer countries, such as the Indian academics, engineers, and doctors who migrate to the United States. Although tangible capital flows in both directions, it is not clear whether, as implied by our analysis, physical capital goes both to richer countries that grow rapidly and do not have particularly low fertility and to poorer countries that do some growing and have high fertility.

An increased stock of human capital raises investments in developing new technologies by expanding the education-intensive research and development industry. Since our analysis implies that human capital grows sharply with development, it readily explains why systematic research and development activities are confined to richer countries.

The rapid growth in the labor force participation of married women is one of the more striking changes induced by economic development during the past half century. Our formal model has only one sex, but it easily incorporates the strong division of labor between married men and women in undeveloped countries, where women spend most of their time bearing and raising many children and doing other work that is complementary to child care. The large decline in birth rates and rise in wage rates as countries develop encourage married women to spend much more of their time in the labor force, which greatly weakens the traditional division of labor.

It has been known for a long time that recovery from wars and other disasters is usually remarkably rapid. John Stuart Mill (1848, p. 74) remarked on "what has so often excited wonder, the great rapidity with which countries recover from a state of devastation, the disappearance in a short time, of all traces of mischiefs done by earthquakes, floods, 
hurricanes, and the ravages of war." He argues that recovery is rapid only when most of the population is left "with the same skill and knowledge which they had before" (p. 75).

Chart 16 shows that a wartime destruction of physical capital in a country that starts along the growth path $(O p)$ stimulates more rapid investment in this capital. It may well also stimulate more rapid investment in human capital; see curve $d$ in chart 16 and the discussion in Section 4 . Then per capita incomes eventually exceed what they would have been had the war not happened, although it still lowers the dynastic utility of the generations alive at the time. This analysis can explain the rapid recovery and then vigorous growth in Germany and Japan after World War II, which suggested to many people the erroneous conclusions that countries benefit from wartime destruction of their physical capital stock.

We can also explain Mill's proviso that knowledge and skills survive. Countries recover from modest reductions in their knowledge, but large enough losses bring a cumulative decline as both physical capital and human capital slide toward an undeveloped state. This happens in chart I6 if human capital is reduced below the manifold through the unstable steady state $W$ (see point $c$ ). Wartime destructions of physical and human capital have different consequences because human capital is knowledge embodied in people. When too much knowledge is destroyed, an economy loses the foundation for further accumulations of knowledgewhether embodied in people or disembodied in technologies-which is the essence of economic growth.

\section{Concluding Remarks}

Our analysis of growth assumes endogenous fertility and a rising rate of return on human capital as the stock of human capital increases. Societies can save across generations by the birth of many children, by great investment in each child, and by long-term accumulation of physical capital. When human capital is abundant, rates of return on human capital investments are high relative to rates of return on children, whereas when human capital is scarce, rates of return on human capital are low relative to those on children. As a result, societies with limited human capital choose large families and invest little in each member; those with abundant human capital do the opposite.

This increasing incentive to invest in human capital as the amount of human capital increases leads to two stable steady states. One has large families and little human capital, and the other has small families and 
large and perhaps growing human and physical capital. A country may switch from the first "Malthusian" equilibrium to the second "development" equilibrium if it has reasonably prolonged good fortune and policies that favor investment.

There is still only a meager understanding of the growth process: of why some countries and regions have grown more rapidly than others and why the growth leaders are not the same in different historical periods. Our analysis appears to highlight important variables in growth and development: investments in human capital, choices over family size and birth rates, interactions between human capital and physical capital, the existence of several stable steady-state equilibria, and the crucial role of luck and the past. Perhaps this analysis will push the understanding of growth a few steps forward.

\section{References}

Arthur, Brian. "Urban Systems and Historical Path Dependence." In Cities and Their Vital Systems: Infrastructure Past, Present, and Future, edited by Jesse H. Ausubel and Robert Herman. Washington: Nat. Acad. Press, 1988.

Barro, Robert J. "Economic Growth in a Cross Section of Countries." Working Paper no. 3120. Cambridge, Mass.: NBER, September 1989.

Becker, Gary S., and Barro, Robert J. "A Reformation of the Economic Theory of Fertility." Q.J.E. 103 (February 1988): 1-25.

Becker, Gary S., and Murphy, Kevin M. "Economic Growth, Human Capital and Population Growth." Paper presented at the conference on the Problem of Development: Exploring Economic Development through Free Enterprise, sponsored by the Institute for the Study of Free Enterprise Systems, State Univ. New York, Buffalo, May 1988.

—_. "Human Capital, the Division of Labor and Economic Progress." Manuscript. Chicago: Univ. Chicago, 1989.

Becker, Gary S., and Tomes, Nigel. "Human Capital and the Rise and Fall of Families." J. Labor Econ. 4, no. 3, pt. 2 (July 1986): SI-S39.

Ben-Porath, Yoram. "The Production of Human Capital and the Life Cycle of Earnings." J.P.E. 75, no. 4, pt. I (August 1967): 352-65.

Bloom, Benjamin S. Human Characteristics and School Learning. New York: McGraw-Hill, 1976.

Chao, Kang. Man and Land in Chinese History: An Economic Analysis. Stanford, Calif.: Stanford Univ. Press, 1986.

David, Paul A. "Clio and the Economics of QWERTY." A.E.R. Papers and Proc. 75 (May 1985): 332-37.

Denison, Edward F. Trends in American Economic Growth, 1929-1982. Washington: Brookings Inst., 1985.

Dowrick, Steve, and Nguyen, Duc-Tho. "OECD Comparative Economic Growth 
1950-85: Catch-ıp and Convergence." A.E.R. 79 (December S1989): 1010-30.

Heckman, James J. "A Life-Cycle Model of Earnings, Learning, and Consumption." J.P.E. 84, no. 4, pt. 2 (August 1976): S1 l-S44.

Jones, Eric L. Growth Recurring: Economic Change in World History. New York: Oxford Univ. Press, 1988.

Jorgenson, Dale W., and Fraumeni, Barbara M. "Investment in Education." Educational Researcher 18 (May 1989): 35-44.

Liıcas, Robert E., Jr. "On the Mechanics of Economic Development." J. Monetary Econ. 22 (July 1988): 3-42.

Meltzer, David O. "Length of Life, Human Capital and Economic Growth." Paper presented at the conference on the Family, Gender Differences and Development, Economic Growth Center, Yale Univ., New Haven, Conn., September 1989.

Mill, John Stuart. Principles of Political Economy, with Some of Their Applications to Social Philosophy. London: Parker, 1848.

Needham, Joseph. The Grand Titration: Science and Society in East and West. London: Allen and Unwin, 1969.

Rosen, Sherwin. "A Theory of Life Earnings." J.P.E. 84, no. 4, pt. 2 (August 1976): S45-S67.

Rosenberg, Nathan, and Birdzell, L. E. How the West Grew Rich: The Economic Transformation of the Industrial World. New York: Basic Books, 1986.

Rostow, Walt W., ed. The Economics of Take-off into Sustained Growth: Proceedings of a Conference Held by the International Economic Association. New York: St. Martin's, 1963.

Schultz, Theodore W. "Capital Formation by Education." J.P.E. 68 (December 1960): 571-83.

Tamura, Robert. "Fertility, Human Capital and the 'Wealth of Nations." Ph.D. dissertation, Univ. Chicago, 1988.

"Fertility, Human Capital and the 'Wealth of Nations.' " Working paper. Iowa City: Univ. Iowa, 1989. 
